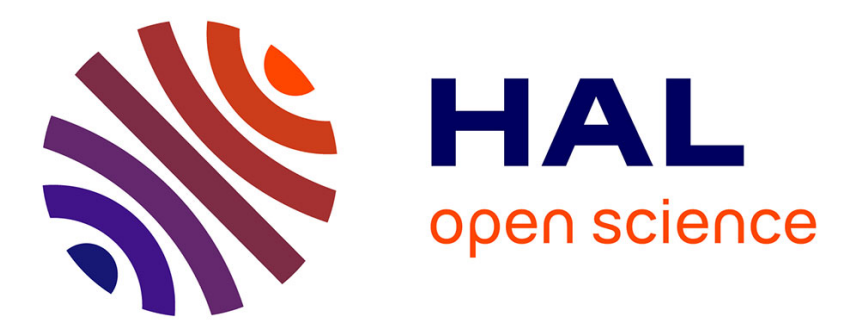

\title{
Predictive Energy Management for Hybrid Vehicles Based on Driving Cycle Recognition
}

Loïc Joud, Daniela Chrenko, Alan Keromnes, Rui da Silva, Luis Le Moyne

\section{To cite this version:}

Loïc Joud, Daniela Chrenko, Alan Keromnes, Rui da Silva, Luis Le Moyne. Predictive Energy Management for Hybrid Vehicles Based on Driving Cycle Recognition. IEEE Vehicle Power and Propulsion Conference (VPPC 2017), Dec 2017, Belfort, France. 10.1109/VPPC.2017.8331052 . hal-03021702

\section{HAL Id: hal-03021702 https://hal.science/hal-03021702}

Submitted on 5 Jan 2022

HAL is a multi-disciplinary open access archive for the deposit and dissemination of scientific research documents, whether they are published or not. The documents may come from teaching and research institutions in France or abroad, or from public or private research centers.
L'archive ouverte pluridisciplinaire HAL, est destinée au dépôt et à la diffusion de documents scientifiques de niveau recherche, publiés ou non, émanant des établissements d'enseignement et de recherche français ou étrangers, des laboratoires publics ou privés.

\section{다)(1) $(5$}

Distributed under a Creative Commons Attribution - NonCommercial| 4.0 International 


\title{
Predictive Energy Management for Hybrid Vehicles based on Driving Cycle Recognition
}

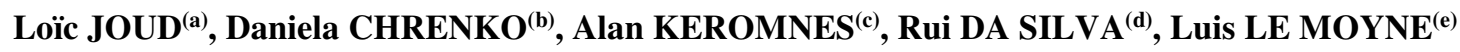 \\ ${ }^{(a, c, e)}$ ID-MOTION DRIVE EA1859, Univ. Bourgogne Franche Comté, 58027, Nevers, France \\ (b) Femto-ST, CNRS, Univ. Bourgogne, Franche-Comte, UTBM, 90010 Belfort, France \\ ${ }^{(\mathrm{a}, \mathrm{d})}$ DANIELSON ENGINEERING, Technopole du Circuit, 58470 Magny-Cours, France \\ (a) $\underline{\text { loic.joud @ danielson-eng.fr, }}{ }^{(\mathrm{b})}$ daniela.chrenko@utbm.fr, ${ }^{(\mathrm{c})} \underline{\text { alan.keromnes@u-bourgogne.fr, }}$ \\ (d) $\underline{\text { ui.dasilva@danielson-eng.fr }},{ }^{(\mathrm{e})} \underline{\text { luis.le-moyne@u-bourgogne.fr }}$
}

\begin{abstract}
This article presents a novel approach to design an optimum energy management for a series plug-in hybrid electric vehicle based on driving cycle recognition. Thanks to an intensive study of driver habits, an important part of cycles is predictable. Optimized energy management can be developed for representative cycles via DP. Those results can be applied to the same cycle with slight adaptations thereafter with quality factors above $98 \%$.
\end{abstract}

Keywords - Plug-In Hybrid Vehicle, Series Hybrid Vehicle, Energy management, Cycle Recognitions, Dynamic Programming

\section{INTRODUCTION}

Facing limitation of resources and global warming, users are forced to find more environmentally sensible, safe and cost effective solutions for their personal transport. Electric vehicles do not yet meet the demands due to limited battery lifetime, long recharge times, lacking recharge infrastructure [1][2] and high cost. However, Plug-in Hybrid Electric Vehicles (PHEV) can be the missing link from conventional to electric vehicles as they can be recharged by both liquid fuel and electricity and their electric autonomy of 30 to $50 \mathrm{~km}$ allows to cover at least $60 \%$ of driving cycles [3][4][5][6]. In order to benefit from their full potential, it is however required that the PHEV arrives at the destination just at the moment when its battery is empty and that electrical energy from renewable sources is available at destination [7][8]. If thermal liquid fuel is used, whereas the cycle could have been covered by electric energy, nonnecessary pollution is created; if the battery is empty before arriving at destination, the internal combustion engine has to cover all working points, reducing the global efficiency [9][10].

Wirasingha and Emadi [9] present an exhaustive analysis of control strategies for PHEVs, but it does not cover aspects of prediction in detail.

The purpose of the present work is to know if a particular effort on the energy management on usual cycles and driver's habits (journeys, speed profile) is meaningful. If it is the case, the goal is to develop a tool in order to optimise the energy flux inside a series hybrid powertrain. This is done by suggesting a management, which identifies usual cycles and which is able to adapt the strategy according to the results of the usual cycle recognition with the goal to reach the best energy distribution along the journey. The work will give rise to an innovative predictive management. Different approaches have been presented [11], [12].

The article is structured as follows: An overview of vehicle use in France is provided in Section II, an analysis of vehicle use in the Nièvre Department is presented in Section III. Section IV presents the energy management including cycle prediction. Conclusions and Perspectives close the article in Section V.

\section{OVERVIEW OF PERSONAL VEHICLE USE IN FRANCE}

In order to define the best strategy, it is first necessary to verify that the use of the vehicle is driven by habits. Figure 1 presents the main displacement reasons in France in 1994 and 2008 [13]. It can be noticed that more than $50 \%$ of the journeys are constrained (work, shopping and study). This distribution is

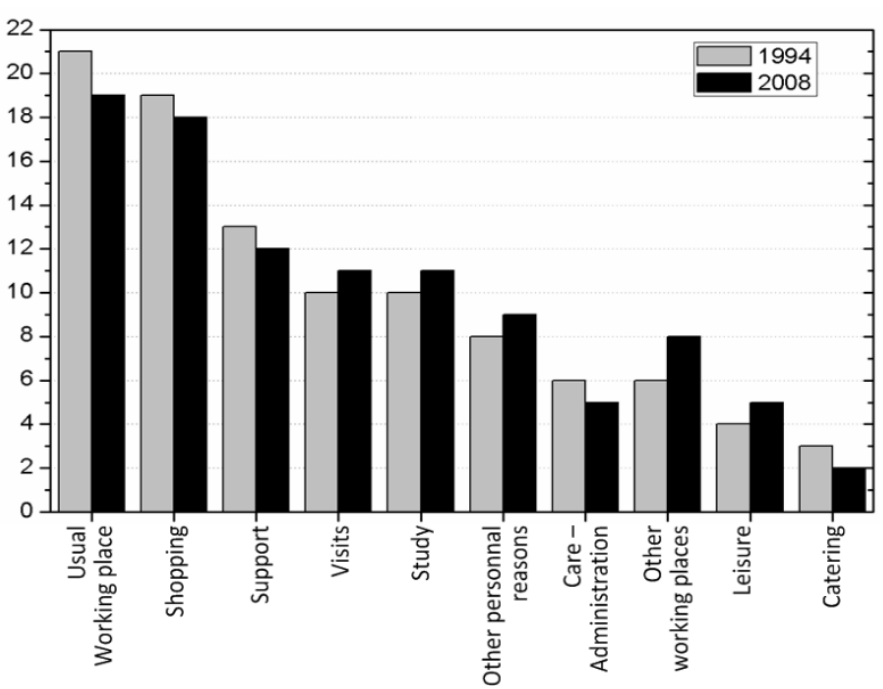

Figure 1: Mobility Evolution of Local displacement reasons on working days in France for people older than 6 years old) [13]

stable over the last decades. Therefore, it might be possible to identify the destinations during working days. Moreover, the average distance of each journey is short (less than $30 \mathrm{~km}$, Table 1) and could be covered electrically by the PHEV.

However, these average values do not give any information about the influence of driver behavior (speed profile, acceleration), which depends also on the car's characteristics (power, weight,...) and will affect the energy management. Even if it is possible to create realistic driving cycles thanks to modeling, it can be interesting to study the real use of vehicles in order to identify if a limited number of cycles is regularly reproduced. Therefore, in order to determine these recurrent cycles and the influence of driving behavior, as well as to verify the previous values in the rural context of the Nièvre 
department in France, it has been decided to perform a mobility study. The approach is presented in the nest section.

\section{ANALYSIS OF VEHICLE USE IN NIEVRE DEPARTMENT}

\section{A. Measurement Approach to Evaluate Vehicle Use}

In order to be able to get significant results which correspond to previous study, it has been necessary to define a panel, which corresponds to the quota method (age, sex) inside the working population of a rural area. In Nièvre, the working population is composed by $47 \%$ of women and $53 \%$ of men and the age distribution is presented in Figure 2. It can be noticed that the working population is equally distributed according to the age criterion between 20 and 60 . Only a few percentage of the workers are older than 60 due to retirement (legal retire age: 62 years). In order to fulfill the criterion a panel of 40 volunteers has been determined and the test were performed over 4 months.

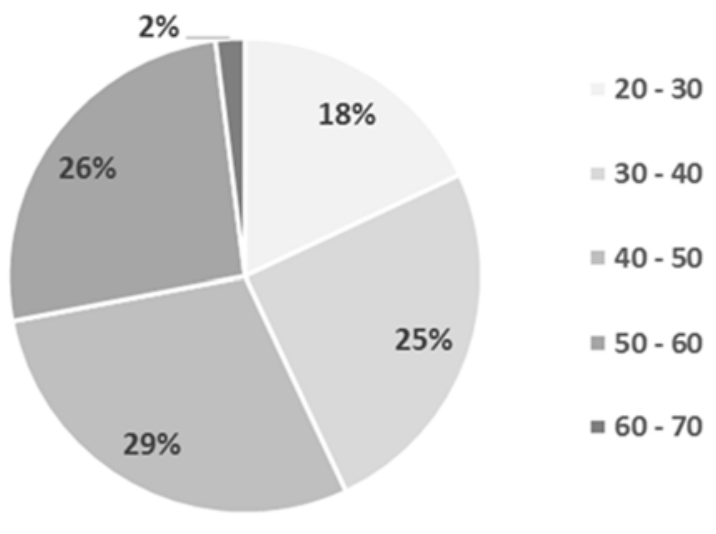

Figure 2: Selection of tested drivers by age

In order to perform the mobility study, ten identical autonomous data acquisition systems have been developed based on Arduino systems. These systems are placed inside the vehicle during one month and do not require any action from the driver. They are composed by a 9 axis inertial unit, a GPS (speed and position) and a 32 Go micro SD card in order to store the data. The power unit is based on 18 Lithium-ion batteries. Data is acquired at a frequency of $10 \mathrm{~Hz}$.

\section{B. Results}

Table 1 : Comparison between Nièvre against mean of France [13]

\begin{tabular}{cccc}
\hline daily & Ref. [13] & This Study \\
\hline Journeys & 3,15 & 3,2 \\
Distance $(\mathrm{km})$ & 29 & $24,6 \pm 4,1$ \\
Duration $(\mathrm{min})$ & 49 & $28,7 \pm 5,5$ \\
Average speed $(\mathrm{km} / \mathrm{h})$ & 35 & $52,2 \pm 10,6$ \\
\hline
\end{tabular}

During the mobility study of 4 months including 40 drivers, a total of 1625 journeys have been performed, which corresponds to over $13,000 \mathrm{~km}$. The results are compared to previous study from [13] in Table 1 on a daily basis in rural areas. It can be noticed that the numbers of journeys and the average daily distance are very similar. However, in the present study the average time is shorter due to a higher average speed. The difference is due to a motorway, which is often used by drivers.

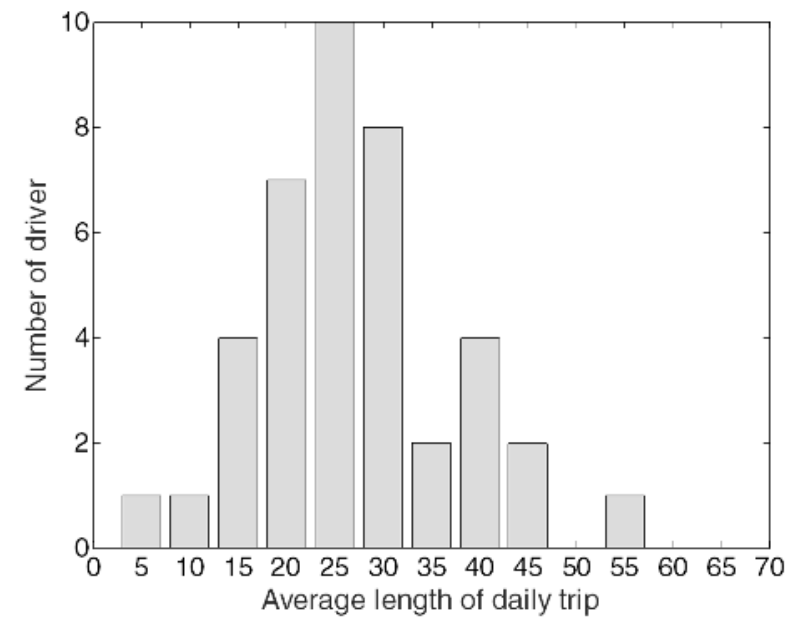

Figure 3: Average daily distance for the drivers in the present study

Detailed results are presented in Figure 3. As mentioned previously, it can be noticed that most drivers travel between 20 and $30 \mathrm{~km}$ per day. However, some drivers are located further away from work and travel up $55 \mathrm{~km}$ per day.

In order to optimize the energy distribution, the first step is to identify if some usual cycles can be determined for each driver. So, a cross-correlation factor is calculated for each driver considering daily repetition. Based on this, it is possible to quantify the number of occurrences of the different trips.

For each starting position, the number of identical journeys is compared to the total number of journeys starting from this point. The identical journeys are determined thanks to a normalized cross-correlation factor, $\sigma$ (equation 1 ) and the journeys are considered to be identical if $\sigma$ is greater than 0.9 . The predictability is defined as the ratio between the cycles with $\sigma$ greater than 0.9 and the total number of cycles starting at this position.

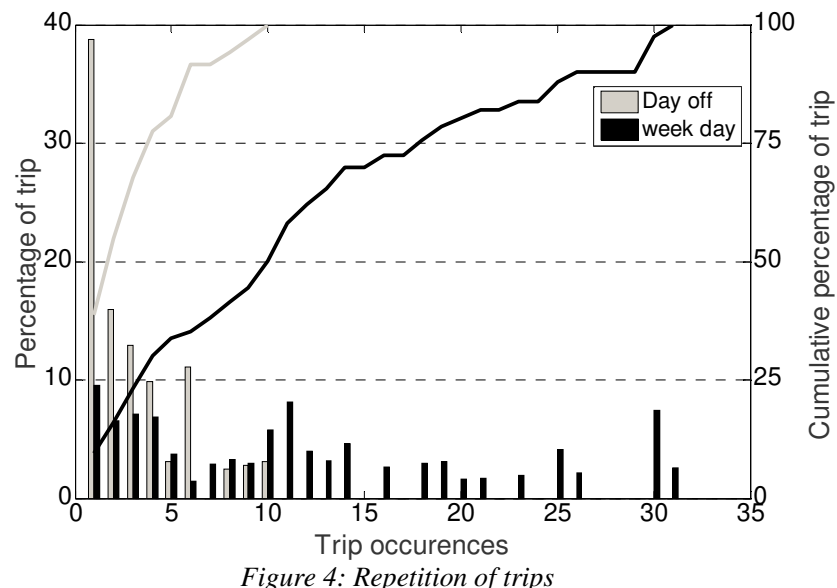

The results (Figure 4) indicate that, on working days, more than $75 \%$ of the trips are performed more than five times. Therefore, it is possible to identify similarities during working days, as presented in Table 2 for all the database and a selection of drivers, since the correlation factor is greater than $82 \%$ during working days. However, drivers' habits are more difficult to identify during week-ends since the overall number of trips is reduced and the number of repetition of the same trip is reduced: $80 \%$ of the trips are performed less than five times. 
Moreover, most journeys are performed during working days since they represent more than $80 \%$ of the journeys (1304 trips for a total trip number of 1625). However, some drivers, such as the woman between 40 and 50 years in Table 2, have a limited journey range and a more important number of journeys with a higher number of destinations. In this case the correlation factor is reduced to $60 \%$. A further analysis of this driver indicates that most journeys are performed in urban areas.

$$
\sigma=\frac{\sum_{x, y}\left[f(x, y)-f_{u, v}\right]\left[t\left(x_{u}, y-v\right)-\bar{t}\right]}{\sqrt{\sum_{x, y}\left[f(x, y)-\overline{f_{u, v}}\right]^{2} \sum_{x, y}\left[t\left(x_{u}, y-v\right)-\bar{t}\right]^{2}}}
$$

Table 2: Comparison of driving habits of 4 drivers during working days and week-ends

\begin{tabular}{cccc}
\hline & $\begin{array}{c}\text { Number of } \\
\text { Journeys }\end{array}$ & $\begin{array}{c}\text { Average } \\
\text { Distance }\end{array}$ & Predictability \\
\hline \multicolumn{4}{c}{ Working days } \\
\hline W 20/30 & 53 & $15 \mathrm{~km}$ & $87 \%$ \\
M 30/40 & 70 & $9,9 \mathrm{~km}$ & $90 \%$ \\
W 40/50 & 80 & $7,5 \mathrm{~km}$ & $60 \%$ \\
M 50/60 & 35 & $5,6 \mathrm{~km}$ & $80 \%$ \\
\hline overall & 1304 & $8,6 \mathrm{~km}$ & $82 \%$ \\
\hline
\end{tabular}

\section{ENERGy MANAGEMENT INCLUDING CYCLE PREDICTION}

The energy management is based on cycle recognition including speed profile. The selected speed cycle is then used inside a vehicle model to determine the energy and power needs during the cycle and optimize the energy management.

\section{A. Cycle prediction}

Since it is possible to identify a repetitive scheme, it is necessary to store and sort the journeys as a function of destination. This will allow the identification of the potential destination as a function of origin and day as well as the determination of the best energy distribution over the journey. Thus, it is necessary to determine a representative speed cycle for a journey. The use of an average speed cycle is not possible since it would completely erase the driver behavior and the speed fluctuations. Therefore, it has been decided to determine among the stored speed cycles for each journey the most representative one based on a cross-correlation criteria calculated from the speed profile. The equation is similar to equation 1. This speed cycle is used to calculate the most efficient energy distribution. Each time a journey is performed, the new speed cycle is stored and compared to previously stored cycles using the cross-correlation. The energy management system only keeps the ten cycles with the highest crosscorrelation criteria. This reduces the impact of chaotic traffic issues (traffic jams, accident and road work) on the speed cycles.

\section{B. Vehicle model}

The vehicle model is based on Energetic Macroscopic Representation (EMR) and its Inversion Based Control (IBC) of a plug-in series hybrid vehicle [14]. The model has been previously validated over the NOAO racing car which was developed and tested in Magny-Cours [15].

This model includes all the different thermal and electrical components of the powertrain and is able to calculate the mass flow rate of fuel and the state-of-charge (SOC) of the battery. The energy and power needs are calculated based on the effort (aerodynamics, inertia, friction) applied on the vehicle and the respect of the speed cycle. Based on the rules used for the energy management in the NOAO, the model reproduces the power profile from the electric machine and the fuel consumption of the internal combustion engine with a very good accuracy. Finally, the maximum difference between the experimental and numerical SOC is below $1 \%$

\section{Optimisation strategy}

It is commonly admitted that Dynamic Programing (DP) is able to provide the best optimization strategy of a system [9], [16]. However, the calculation time makes it impossible to use on-line. Therefore, Dynamic Programming is used off-line at the end of the journey in order to determine which would have been the best energy management along the journey taking into account the state-of charge of the battery and the fuel consumption. In order to verify the potential gain thanks to DP, it has been used in order to calculate the best energy management and the resulting fuel consumption for each cycle. The results are presented for a selection of five similar cycles of the same journey in Table 3. For those similar cycles, the energy management determined using DP for the most representative cycle (i.e. cycle 5 determined by crosscorrelation) has been applied for the other occurrences of this cycle. This results in an increase of the fuel consumption by up to $7 \%$ according to the cycle when compared to the DP calculation of the cycle. Therefore, a blind application of DP is not the best strategy.

Table 3: Impact of DP strategy on fuel consumption for $9.2 \mathrm{~km}$ journey with an average speed of $44 \mathrm{~km} / \mathrm{h}$ for a starting SOC of 0.54 and finishing at 0.37

\begin{tabular}{|c|c|c|c|c|c|}
\hline Cycle & 1 & 2 & 3 & 4 & 5 \\
\hline $\begin{array}{l}\text { Correlation } \sigma \\
\quad \text { (speed) }\end{array}$ & 0,983 & 0,979 & 0,976 & 0,981 & 1 \\
\hline $\begin{array}{c}\text { DP Fuel } \\
\text { consumption (L) }\end{array}$ & 0,73 & 0,64 & 0,61 & 0,73 & 0,70 \\
\hline $\begin{array}{c}\text { Cycle } 5 \text { strategy } \\
\text { (L) }\end{array}$ & 0,79 & 0,67 & 0,65 & 0,77 & 0,70 \\
\hline $\operatorname{Gap}(\%)$ & 7,5 & 4,4 & 6,1 & 5,2 & / \\
\hline
\end{tabular}

A second optimization strategy, based on least square minimization, has been implemented in order to adapt the

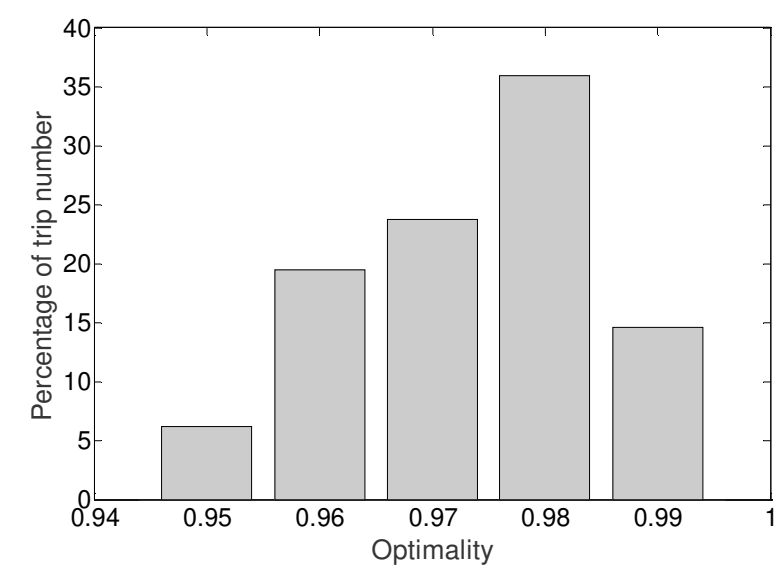

Figure 5: Distribution of the optimality reached thanks to the optimization

energy management online during the journey. The method minimizes the difference between (i) the optimal consumption calculated thanks to DP on the most representative cycle and 
(ii) the consumption obtained with the energy repartition chosen at time t. The algorithm also calculates the energy management over a foreseeable window. An optimality factor has been determined in order to compare the fuel consumption determined by the strategy with the optimum fuel consumption calculated off-line thanks to dynamic programming. This factor corresponds to the fuel consumption predicted by DP divided by the consumption obtained thanks to the optimization. As an example, when applying this new optimization strategy to cycle number 1 , it has been possible to reach a fuel consumption of $0,742 \mathrm{~L}$. This represents an optimality factor of 0.983 . The extension of this strategy to the experimental database is presented in Figure 5. It is possible to reach an optimality factor greater than 0.95 for all the speed cycles of the database recorded during week days (Figure 5).

\section{CONCLUSION AND PERSPECTIVES}

The present study aims at developing an optimization tool in order to obtain a predictive energy management inside a plug-in series hybrid vehicle. An experimental investigation of mobility revealed the more than $82 \%$ of the displacement can be predicted during working days due to constrained mobility. Therefore, the optimization strategy could be applied in order to reduce the fuel consumption thanks to the prediction of the journey based on a cross correlation calculation.

The optimization strategy has been compared to the energy management calculated thanks to dynamic programming using an energetic macroscopic representation of the vehicle. The developed optimization strategy allows to reach at least $95 \%$ of the optimality predicted by dynamic programing.

In the future, the prediction of the speed cycle will be made more precise since it will take into account the starting time. Moreover, in order to improve the prediction, the instantaneous location will be compared to stored starting position in order to calculate the optimization strategy based on a larger database and include more speed cycle. This will also allow a better prediction and a reduced fuel consumption when the journey is performed for the first time.

\section{ACKNOWLEDGEMENTS}

The authors want to acknowledge all the volunteers who participate to the mobility investigation and the Burgundy Council for the financial support via ID-Motion laboratory.

\section{REFERENCES}

[1] T. Devloo, N. Leemput, G. S. Member, J. Van Roy, F. Geth, J. Driesen, and S. Member, "Component Improvements in the Electrification of Passenger Vehicles Drivetrains," no. 3, 2013.

[2] J. Barkenbus, "Our electric automotive future: $\mathrm{CO} 2$ savings through a disruptive technology," Policy Soc., vol. 27, no. 4, pp. 399-410, Mar. 2009.

[3] S. G. Wirasingha, N. Schofield, and A. Emadi, "Plug-in hybrid electric vehicle developments in the US: Trends, barriers, and economic feasibility," 2008 IEEE Veh. Power Propuls. Conf., pp. 1-8, 2008.

[4] E. Ericsson, "Independent driving pattern factors and their influence on fuel-use and exhaust emission factors," Transp. Res. Part D, vol. 6, pp. 325-345, 2001.

Res. Part D, vol. 5, pp. 337-354, 2000.

[6]

[8] Q. Gong, Y. Li, and Z. R. Peng, "Trip Based Power Management of Plug-in Hybrid Electric Vehicle with TwoScale Dynamic Programming," in IEEE Vehicle Power and Propulsion Conference, 2007, pp. 12-19.

[9] S. G. Wirasingha and A. Emadi, "Classification and Review of Control Strategies for Plug-In Hybrid Electric Vehicles," IEEE Trans. Veh. Technol., vol. 60, no. 1, pp. 111-122, Jan. 2011.

[10] V. Larsson, L. J. Mårdh, B. Egardt, and S. Karlsson, "Commuter Route Optimized Energy Management of Hybrid Electric Vehicles,” vol. 15, no. 3, pp. 1145-1154, 2014.

[11] D. Filev, F. Tseng, and R. Mcgee, "Contextual On-Board Learning and Prediction of Vehicle Destinations," 2011.

[12] Q. Ye, L. Chen, and G. Chen, "Predict Personal Continuous Route," pp. 587-592, 2008.

[13] "Commissariat Général au Développement Durable", "La mobilité des Français : Panorama issue de l'enquête nationale transports et déplacements 2008."

[14] L. Jin and W. Wang, "The control strategy and cost analysis for series Plug-in hybrid electric vehicle," 2010 2nd Int. Conf. Adv. Comput. Control, pp. 350-354, 2010.

[15] Z. Asus, D. Chrenko, E.-H. Aglzim, A. Kebairi, A. Keromnes, and L. Le Moyne, "Model and Control Strategy Simulation of a Racing Series Hybrid Car," in IEEE Vehicular Power and Propulsion Conference VPPC, 2014.

[16] D. Chrenko, S. Gan, C. Gutenkunst, R. Kriesten, and L. L. E. Moyne, "Novel Classification of Control Strategies for Hybrid Electric Vehicles," 2015. 